\title{
The Importance of Graphology In Determining Of The Managerial Qualities Of The Future Women Leaders Within The Z Generation: A Research Done On International Business Management Students Of Coventry University
}

Res. Asst. Betül SOLMAZ

Istanbul University, Department of Labor Economics,

Neriman KARA

Graphologist,

Özlem KARTAL

Ministryof Family and Social Politics

\begin{abstract}
The $Z$ generation is a name given for the progeny born after the year 1995 and this generation is seen to be extremely different to the previous ones. This generation is yet to take place in the world of work. Their qualities therefore are different to the previous generations. The qualities evolving differently in comparison to the previous generations qualities will also take their place within the world of work approaching. Especially for the division within the $\mathrm{Z}$ generation who will take the path of leadership and management in their careers, graphology plays a great part in analysing their characteristics and qualities to see if they fit the leadership position they are aiming to achieve. Graphology can be described as signature and handwriting analysis used to help with analysing the character of individuals. Not every individual is deemed to have leadership characteristics and qualities. Those, who hold characteristics that consist leadership within them, becoming managers is considered extremely important within the organizational culture and the maintaining of the organizational structures. This research will contain of the signature analysis of 17 female International Business Management students, within the $\mathrm{Z}$ generation. The result will show whether their characteristics and qualities are fit, or unfit for the course they are undertaking. In addition to the research, if the results are meaningful in this case, it will be debated whether the science of signature analysing is compatible with the division of the students who choose to study in the international business management department. The evaluation of the received Signatures is thought to be an analysis of the personality structures of these individuals, which will be effective in career management as well as career success and motivation.
\end{abstract}

Keywords: Z Generation, Woman, Young, Graphology, Career management, Management.

\section{Introduction}

In the coming years, the $Z$ generation is the generation that will play an active role in the world of business. The $Z$ belt generation following on from the $Y$ belt, is preparing to take its place in the business world. Future employees, executives and leaders will come from this generation. The purpose of this study; is to show that the character structure of the $Z$ generation differentiate with other generations and shows how individual characteristics such as individualistic attitudes, self-confident structures, and high ability to solve problems are in accordance with the analysis of the signatures of leadership structures. Graphology (signature / writing) helps in determining the personality analysis of individuals. With signature analysis, individuals with leadership qualities will have an advantage in the name of companies that compete in 
the global market, where they are well-defined in the company they are in. The study examined the analysis of signatures of the z-belt female students who study International Business Management at Coventry University to see if there are leadership qualities within them and how effective and relative the course they are undertaking is to them.

\section{Generation Z}

The generation is often described as a determinative group that shares the year of birth, age, and significant life events in the critical developmental stages (Cooman, Dries, 2012: 44).

The generations; should be classified using the beliefs, feelings and experiences of the community that formed the generations and not only according to the time periods they were born in. (Zemke, Raines, Filipczak,2013: 4).

In Literature, the generations differ according to countries and historical events. The Z-belt is accepted as literate in the post-1990, 1995, and 2000 years. The ones born in 1995 and beyond were taken as the Z-belt for our research. Generally accepted belt classifications are as follows (Cooman and Drics, 2012: 44);

- The Silent Generation (1925-1944) .

- Baby Boom (1945-1964)

- Generation X (1965-1979)

- Generation Y (1980-1994)

- Generation Z (1995 -...)(academia.edu)

Generation $Z$ is also referred to by different names; Strauss and Howe describe it as "The New Silent Generation"(Strauss, Howe, 1999: 335), also; Gen Z, Zs, Gen Z 'ers, iGeneration, Gen Tech, Gen Wii, Net Gen, Digital Natives, Gen Next, Post Gen, and Plurals were used (Wiedmer, 2015:55).

This generation is raising in an environment where Internet is very common. This situation is reflected in their characteristic features. Internet is indispensable for this generation that is interwoven with computers and technology. They interfere with the internet, social media and mp3 players, text messaging, mobile phones, PDAs, YouTube, IPADs, media technologies on a day to day basis. They can be named as the mobile generation. (Kapil and Roy, 2014: 10-11.)

The characteristics that are emerging from the $Z$ belt are, Tech Savvy, Prematurely mature, Pampered, Empowered, Risk adverse, Protected (Singh, 2014: 59), The 7 characteristics features of the $Z$ belt are: Cynical, private, Entrepreneurial, Multi-tasking, Hyper-aware, Technology-reliant ( growingleaders.com).

\section{Leadership}

Approaches developed in relation to leadership, define leadership in terms of characteristics, behavioural characteristics the person has in conditions / situations and their circumstances (Çelik, 2000: 1).

Leadership is more than being reasonable it is using intelligence to make things reasonable, it is to put in to practice a very neutral choice instead of involving anxiety and fear into work. (Williams, 2006: 213).

The features that must be found in a successful leader can be presented as (Aydın, 1997: 86):

- The leader has a personality structure that has developed a sense of self-confidence which also reflects onto those who follow him.

- A Leader, is someone who can choose the right solutions in accordance with the conditions, fast in making decisions and reaching the broadest alliance in implementing these decisions. 
- A Leader is, stable, precise, responsible and someone whose social adaptation skills are developed.

- Leader is the person who has blended and assimilated the features of control, devotion, distant vision, intuition, and courage to themselves.

- The leader is the person who observes the events and has the potential to communicate verbally with his followers, establishes cause-effect relationship, is close to cooperation and has a high technical understanding.

- A Leader is creative, intelligent, entrepreneurial, sociable, and idealistic.

- A Leader is an active executive who organizes group members, has a high level of knowledge and skill, and is in control.

- The leader is the person with the ability to control emotions in a balanced and consistent personality.

- A Leader, has a sense of unity and solidarity within the group; the person who is sensitive to the event, situation, and person. A person with empathy.

- The leader is open and respectful of prejudice, criticism, and contrary views. The leader is an effective speaker and a good listener.

- A Leader is a person with a high sense of accomplishment and motivation.

-A Leader holds a multidimensional perspective, abstract thinking capacity is strong.

According to another source; The 7 observable features of the leader are listed as follows (Williams, 2006: 52).

1-Developed in skills, abilities, and quickness.

2-The anticipation that allows them to see the next step is high, they depend on their purposes and are loyal.

3-They have assimilated self-discipline and self-esteem.

4-They are an accomplished and capable individual.

5-Responsibility and acceptance of liability.

6 -They have developed their ability to communicate effectively.

7-They set an example with their behaviours.

\section{Graphology}

Graphology is applied to many fields today. Personality analysis, intellectual-behavioural and emotional-related aspects in adults, psycho-emotional problems, compatibility studies in families in married couples, academic and vocational guidance, business counselling, handwriting, signatures, and expert opinion in courts. Graphologists have been involved in the recruitment process in many countries and in the selection of human resources personnel (Dazzi, Pedrabissi, 2009: 1).

There are several principles that graphology is based on. These are (dergiler.ankara.edu.tr):

- Everyone has a unique handwriting.

- Everyone's characteristics reflect in their handwriting.

- Every person has unchangeable characters in their writing.

Graphology is the science of handwriting and in analysing personal characteristics and features of people it is an important factor, as such as their words, body language, photos being some of the deciding factors graphology is also a key in the 
analysis of personality characteristics. The mind initially motivates the writing. Writing work has an analytic significance in coping with mind and body (Amend, Ruiz, 1980: V).

\section{Material}

In our research, the $\mathrm{z}$ generation, who are studying International Business Management at Coventry University, was selected from the 1st year female students. The total number of students who are undertaking their first year in the International Business Management course is 112, 43 of the 112 of these students are females. We have selected 17 of these female students to analyse for our research. The age difference varies between 18 and 21,11 of the selected students are 19 years old.

Ethnic backgrounds of the participants differ along; Polish, Bulgarian, Turkish, British, Arab, Portuguese, Cuban, French, Latvian, Nepalese, Danish, Chinese, Norwegian, Pakistani.

\section{Application}

In this study, the selected 17 female students of the $z$ belt age group had their signatures analysed to observe whether they hold any leadership qualities and features. Also, they were examined to see whether they were compatible with the characteristics of the course they have chosen to study at university.

Leadership features in the study are divided into 4 groups. These include: personnel characteristic, mental characteristic, emotional features, general features.

The results are as follows:

Personal Characteristics: The fact that selected students have resulted in having more empathetic feelings is striking. It is then seen that interpersonal relations also have a high rate. The high level of inter-personal dialogue in the literature of the Z-belt is in accordance with the conclusion of our study that the communication abilities are high.

Mental Characteristic: When the mental characteristics of 17 female students were examined, the high emergence of their 'will' being consistent in accordance with the characteristics of the z-belt individuals in the literature. Intelligent and intellectual structures are high and entrepreneurship ability is seen to be low in some of the selected students.

Emotional Features: the analysis of self-control and self-knowledge seems to be at a high level. Consistency rates are moderate.

General Features: especially the leadership feature which is the subject of our research, has been high in all signatures as the result of the analysis made. Motive ability to result in the same rate is complementing their leading features

Table 1: Managerial Characteristics

\begin{tabular}{lll}
\hline \hline & & Person \\
Personal Characteristics & Interpersonal Relations & 15 \\
& Communication Capability & 14 \\
& Precision & 12 \\
& Stability and Ability to Manage People & 11 \\
& Creativity & 15 \\
& Systematic Thinking & 13 \\
& Empathy & 16 \\
\hline \hline Mental Characteristics & Will & 17 \\
& Individual Discipline & 15 \\
& Initiative & 8 \\
& Reasoning & 16 \\
& Self-Confidence & 11 \\
& Intelligence & 17
\end{tabular}




\section{Conclusions}

It has been determined that the leadership characteristics of the signatures analysed in this study are quite high in the selected z-belt individuals. When the personal characteristics were examined, it is seen that the characteristics of the zbelt in the literature are meaningful and applicable to our work. This study shows that the leadership of z-belt individuals is high, and at the same time, they hold characteristics that are in accordance, it is a positive development for the individuals who will take on leading positions in the future. We can say that the students with signatures are from different nationalities, meaning that the general characteristics of the z-generation individuals in the international sense do not vary much. Although the political culture and the economic structure of each country are different, according to the result of our work, there are a common point of $z$ generation in the present world. The $Z$ generation is self-confident, governed with strong leadership skills, more sensitive to the environment, intelligent, entrepreneurial, and open-minded. The things that today's $z$ generation wants are more sensitive to make the world a more liveable place than the previous generations. Another result to this research is; that there is a consistent level of leadership skills within this generation that should allow them to achieve some if not better levels in the roles that they undertake.

\section{References}

[1] Anjali Singh, "Challenges and Issues of Generation Z", IOSR Journal of Business and Management (IOSRJBM), Volume 16, Issue 7. Ver. I (July. 2014), PP 59-63

[2] A.Aydin, "Liderliginn Temel Nitelikleri Nelerdir?", (21. Yüzyılda Liderlik Sempozyumu), Bildiriler Kitabı, Birinci Basım, İkinci Cilt, İstanbul, 1997.

[3] Carla Dazzi And Luigi Pedrabissi, "Graphology And Personality: An Empirical Study On Validity Of Handwriting Analysis", Psychological Reports, 2009, 105, 3, P.1255, Pp.1255-1268.

[4] Karen Kristin Amend and Mary Stansbury Ruiz, Handwriting Analys, The Complete Basic Book, 1980

[5] Kapil Y., Roy , A. (2014), "Critical Evaluation of Generation Z at Workplaces", International Journal of Social Relevance\&Concern, Volume 2, Issue1, , p.10-11., pp.10-14.

[6] Michael Williams "Mastering Leadership", Second Edition, Thorogood Press, UK, 2006.

[7] Rein De Cooman and Nicky Dri e s, Attracting Generation Y: How Work Values Predict Organizational Attraction in Graduating Students in Belgium,, Ed. Eddy S. Ng, Lyons T.Sean vd., Managing th New Workforce, UK,p.44., 2012. S.44-63.

[8] Strauss, W. ve S. Howe. (1999). Generations: The history of America's future, 1584 to 2069. New York: Quill/William/Morrow ,s.335

[9] Terry Wiedmer, "Generations Do Differ: Best Practices in Leading Traditionalists, Boomers, and Generations X, Y, and Z", Academic Journal Article, 2015, p.51-58.

[10] Vehbi Çelik, "Egıtimsel Liderlik", Pegem Yayıncılık, Ankara, 2000.

[11] Zempke Ron, Raines Claire, Filipczak Bob, Generations at Work: Managing the Clash of Boomer, Gen X ers, Gen Y ers in the Workplace, 2nd. Ed., Amacom, USA, 2013., s.4.

[12] http://www.academia.edu/2340731/ Z ehir gibi bir kuşak

[13] http://dergiler.ankara.edu.tr/dergiler/26/1244/14211.pdf

[14] https://growingleaders.com/blog/six-defining-characteristics-of-generation-z/ 